\title{
High performance midinfrared narrow-band plasmonic thermal emitter
}

\author{
Ming-Wei Tsai, Tzu-Hung Chuang, Chao-Yu Meng, Yi-Tsung Chang, and Si-Chen Lee ${ }^{a)}$ \\ Department of Electrical Engineering, Graduate Institute of Electronics Engineering, National \\ Taiwan University, Taipei, Taiwan 106, Republic of China
}

(Received 17 April 2006; accepted 13 September 2006; published online 25 October 2006)

\begin{abstract}
The blackbody radiation spectrum is fundamental to any thermal emitter. However, by properly designing the emitter structure, a narrow bandwidth and high power infrared source can be achieved. This invention consists of a triple layer structure by sandwiching a dielectric $\mathrm{SiO}_{2}$ layer between two Ag metal films on the Si substrate. The top Ag layer is perforated by periodic holes. When the device was heated, the background thermal radiation was suppressed by the bottom Ag whose emissivity is very low. The thermal radiation generated in the $\mathrm{SiO}_{2}$ layer resonant between two metal films and the $\mathrm{Ag} / \mathrm{SiO}_{2}$ and the $\mathrm{Ag} /$ air surface plasmon polaritons are induced and converted to light radiation. Strong resonance at $\mathrm{Ag} / \mathrm{SiO}_{2}(1,0)$ degenerate modes results in the coherent light radiation at the wavelength associated with the dielectric constant of $\mathrm{SiO}_{2}$ and the lattice constant of the perforated hole array. The ratio of the full width at half maximum to the peak wavelength is 0.114 . This narrow bandwidth and high power infrared light source can be used to explore the biological response of cells and plants. (C) 2006 American Institute of Physics. [DOI: 10.1063/1.2364860]
\end{abstract}

Extraordinary transmission through periodic subwavelength perforated hole arrays in metallic films has been reported by Ebbesen and co-workers. ${ }^{1,2}$ In recent years, experimental and theoretical works on near-field image, ${ }^{3-5}$ dispersion relation of the surface plasmon polariton (SPP), ${ }^{6-8}$ and time domain analysis ${ }^{9,10}$ are focused on the investigation of the coupling mechanisms of surface plasmons (SPs) with the periodic structure. Extraordinary optical transmission through two-dimensional periodic, corrugated metallic films without holes has been reported theoretically and experimentally, ${ }^{11,12}$ which reveals the coupling of surface plasmon waves excited simultaneously on both sides of the metallic thin film. A thermal emitter with narrow bandwidth emission property is very useful in the studies of the reaction of a biological system, environmental protection, and industrial environment. ${ }^{13-19}$ The maximum transmission of a cascaded metallic structure, the dielectric layer sandwiched between two metal films, can be more than $400 \%$ greater than that of a corresponding single metallic structure. ${ }^{20}$ In this letter, the high performance plasmonic thermal emitters were proposed and fabricated. Their thermal radiation and the coupling mechanism with SPs were investigated in detail.

A double layer consisting of a $50 \mathrm{~nm} \mathrm{Cr}$ followed by $100 \mathrm{~nm} \mathrm{Au}$ films is thermally deposited on the back of the double-polished $\mathrm{Si}$ substrate as a heating source. Ag metal film was deposited on the front side of the Si substrate followed by a $\mathrm{SiO}_{2}$ layer deposited with the electron beam evaporator. The thicknesses of the $\mathrm{SiO}_{2}$ layer in devices $\mathrm{A}$, $\mathrm{B}$, and $\mathrm{C}$ are 100,300 , and $500 \mathrm{~nm}$, respectively. Then a hexagonal hole array of $100 \mathrm{~nm}$ thick silver film was deposited and lifted-off on $\mathrm{SiO}_{2}$ layer with the lattice constant $a$ of $3 \mu \mathrm{m}$ and diameter $d$ of $1.5 \mu \mathrm{m}$. The radiation area of the sample is $1 \mathrm{~cm}^{2}$. The schematic diagrams showing the side and top views of the device structure are depicted in Figs. 1(a) and 1(b), respectively. A Perkin Elmer 2000 Fourier transform infrared spectrometer (FTIR) system was adopted

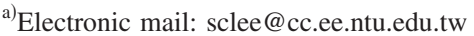

to measure thermal radiation spectra. The wave number resolution of the measurement was $8 \mathrm{~cm}^{-1}$.

In a two-dimensional hexagonal lattice, the conservation of momentum for SPs is given by

$$
\mathbf{k}_{\mathrm{SP}}=\mathbf{k}_{x}+i \mathbf{G}_{1}+j \mathbf{G}_{2},
$$

where $\mathbf{k}_{\mathrm{SP}}$ is the wave vector of the surface plasmon given by

$$
\left|\mathbf{k}_{\mathrm{SP}}\right|=\frac{\omega}{c}\left(\frac{\varepsilon_{1} \varepsilon_{2}}{\varepsilon_{1}+\varepsilon_{2}}\right)^{1 / 2}
$$

where $\omega$ is the frequency of the surface plasmon that is excited by the incident radiation with frequency $\omega$, $\mathbf{k}_{x}=\left|\mathbf{k}_{0}\right| \sin \theta,\left|\mathbf{k}_{0}\right|=2 \pi / \lambda$ is the wave vector of the incident radiation, and $\lambda$ is the wavelength of the radiation in vacuum. $\theta$ is the incident angle with respect to the normal direction of the surface. $\varepsilon_{1}$ and $\varepsilon_{2}$ are the dielectric constants of the insulator $\mathrm{SiO}_{2}$ and the metal $\mathrm{Ag}$, respectively. $\mathbf{G}_{1}$ and $\mathbf{G}_{2}$ are the reciprocal lattice vectors of a hexagonal lattice, and $i$ and $j$ are integers. For normal incident light, $\theta=0^{\circ}$ and $\mathbf{k}_{x}=0$, Eq. (2) reduces to

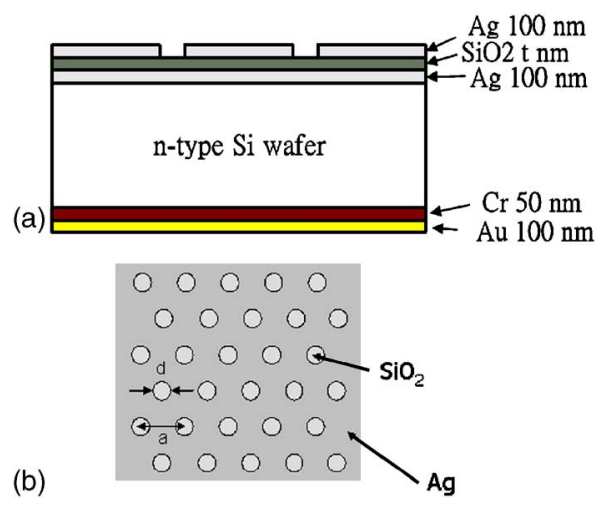

FIG. 1. (Color online) Schematic diagram of the (a) side and top views of the devices. The thicknesses $t$ of $\mathrm{SiO}_{2}$ layer in devices $\mathrm{A}, \mathrm{B}$, and $\mathrm{C}$ are 100 , 300 , and $500 \mathrm{~nm}$, respectively. The hexagonal hole array has a lattice constant $a$ of $3 \mu \mathrm{m}$ and diameter $d$ of $1.5 \mu \mathrm{m}$. 


$$
\lambda=a\left(\frac{4}{3}\left(i^{2}+i j+j^{2}\right)\right)^{-1 / 2}\left(\frac{\varepsilon_{1} \varepsilon_{2}}{\varepsilon_{1}+\varepsilon_{2}}\right)^{1 / 2} .
$$

The real parts of the dielectric constants of $\mathrm{Ag}$ at 2, 3, 4, and $5 \mu \mathrm{m}$ are $-2.1 \times 10^{2},-4.71 \times 10^{2},-8.34 \times 10^{2}$, and $-1.31 \times 10^{3},{ }^{21}$ respectively. That of $\mathrm{SiO}_{2}$ is 2.13 at all of these wavelengths. The calculation results show that the $( \pm 1,0), \mathrm{Ag} / \mathrm{SiO}_{2},(0, \pm 1) \mathrm{Ag} / \mathrm{SiO}_{2},(-1,1) \mathrm{Ag} / \mathrm{SiO}_{2}$, and $(1,-1) \mathrm{Ag} / \mathrm{SiO}_{2}$ modes are degenerate and located at $3.79 \mu \mathrm{m}$, the $\mathrm{Ag} / \mathrm{SiO}_{2}(1,1)$ mode at $2.19 \mu \mathrm{m}$, and the $\mathrm{Ag} /$ air $(1,0)$ modes at $2.6 \mu \mathrm{m}$, assuming that the $\mathrm{SiO}_{2}$ layer is infinitely thick.

The devices are heated by sending electric current through the back $\mathrm{Cr} / \mathrm{Au}$ metal on $\mathrm{Si}$ substrate. The thermal radiation generated in the $\mathrm{SiO}_{2}$ layer resonates between the two metal films and the $\mathrm{Ag} / \mathrm{SiO}_{2}$ and $\mathrm{Ag}$ /air SPPs are induced and then converted to light radiation. The emission spectra were measured at different temperatures from 220 to $300{ }^{\circ} \mathrm{C}$ and shown in Figs. 2(a)-2(c) for devices A, $\mathrm{B}$, and $\mathrm{C}$, respectively. In the inset of Fig. $2(\mathrm{a})$, the $300{ }^{\circ} \mathrm{C}$ emission spectrum is enlarged. The peak at $4.16 \mu \mathrm{m}$ is the degenerate modes composed of $( \pm 1,0) \mathrm{Ag} / \mathrm{SiO}_{2},(0, \pm 1)$ $\mathrm{Ag} / \mathrm{SiO}_{2},(-1,1) \mathrm{Ag} / \mathrm{SiO}_{2}$, and $(1,-1) \mathrm{Ag} / \mathrm{SiO}_{2}$ modes. The degenerate modes around $2.45-2.8 \mu \mathrm{m}$ are composed of $( \pm 1,0) \mathrm{Ag}$ /air, $(0, \pm 1) \mathrm{Ag}$ /air, $(-1,1) \mathrm{Ag} /$ air, and $(1,-1) \mathrm{Ag} /$ air modes. The bottom $100 \mathrm{~nm}$ thick Ag film has very small emissivity which generates very small blackbody radiation, yet it can completely block the background radiation from the $\mathrm{Si}$ substrate. The $\mathrm{Ag} / \mathrm{SiO}_{2}$ and $\mathrm{Ag}$ /air SPPs are induced in the top $\mathrm{Ag}$ layer. The full width at half maximum (FWHM) of the $\mathrm{Ag} / \mathrm{SiO}_{2}(1,0)$ degenerate mode is $0.48 \mu \mathrm{m}$. The ratio of the FWHM to the peak wavelength is 0.114 which is small. The power consumption is about $18.52 \mathrm{~W}$ at the temperature of $300{ }^{\circ} \mathrm{C}$, total output power measured at the FTIR system is $384 \mathrm{~mW}$, and the output power to input power ratio is $2.1 \%$. The narrow-band emitter has been demonstrated by Pralle et al. ${ }^{13}$ strong resonance at air/Au SPP $(1,0)$ degenerate modes results in the light radiation at the wavelength equaling the lattice constant. However, in Figs. 2(a)-2(c), much stronger resonance at $\mathrm{Ag} / \mathrm{SiO}_{2}(1,0)$ degenerate modes at $4 \mu \mathrm{m}$ as compared to $\mathrm{Ag} /$ air $(1,0)$ degenerate modes at $2.45 \mu \mathrm{m}$ was demonstrated. The peak wavelengths at the $\mathrm{Ag}$ /air and $\mathrm{Ag} / \mathrm{SiO}_{2}$ modes in devices $\mathrm{A}, \mathrm{B}$, and $\mathrm{C}$ remain unchanged when the temperature increased from 220 to $300{ }^{\circ} \mathrm{C}$, implying that the SP coupling mechanisms are the same. More light is generated in the thicker $\mathrm{SiO}_{2}$ layer and the degenerate $(1,0) \mathrm{Ag} / \mathrm{SiO}_{2}$ modes are easier to distinguish. The peak located at $3 \mu \mathrm{m}$ shown in Fig. 2(c) is due to the cross coupling ${ }^{22}$ of the $\mathrm{Ag} / \mathrm{SiO}_{2}$ and $\mathrm{Ag}$ /air modes which become distinguishable in the thicker $\mathrm{SiO}_{2}$ layer. Figure 2(d) displays the band structure of the $\mathrm{Ag} / \mathrm{SiO}_{2}$ and $\mathrm{Ag} /$ air plasmon modes along the $\Gamma M$ and $\Gamma K$ directions, where $M$ is located at $2 \pi / a(1,0)$ and $K$ is located at $2 \pi / a(1$, $-1 / \sqrt{3})$ in the reciprocal space. It can be seen that the $(0,1),(1,0) \mathrm{Ag} / \mathrm{SiO}_{2}$ degenerate modes cross over the $(-1,0),(0,-1) \mathrm{Ag} /$ air degenerate modes at $0.4 \mathrm{eV}$ along the $\Gamma M$ direction. Similarly, the $(1,0)$ and $(-1,0),(0,-1)$ $\mathrm{Ag} / \mathrm{SiO}_{2}$ modes cross over the $(-1,0) \mathrm{Ag} /$ air mode at $0.4 \mathrm{eV}$ along the $\Gamma K$ direction. This means that the $\mathrm{Ag} / \mathrm{SiO}_{2}$ modes resonate with the $\mathrm{Ag} / \mathrm{air}$ modes at a specific direction. The FTIR experiment is a far-field measurement. The emission solid angle collected in the system is about $30^{\circ}$, therefore, in Downloaded 04 Mar 2009 to 140.112 .113 .225 . Redistribution subje
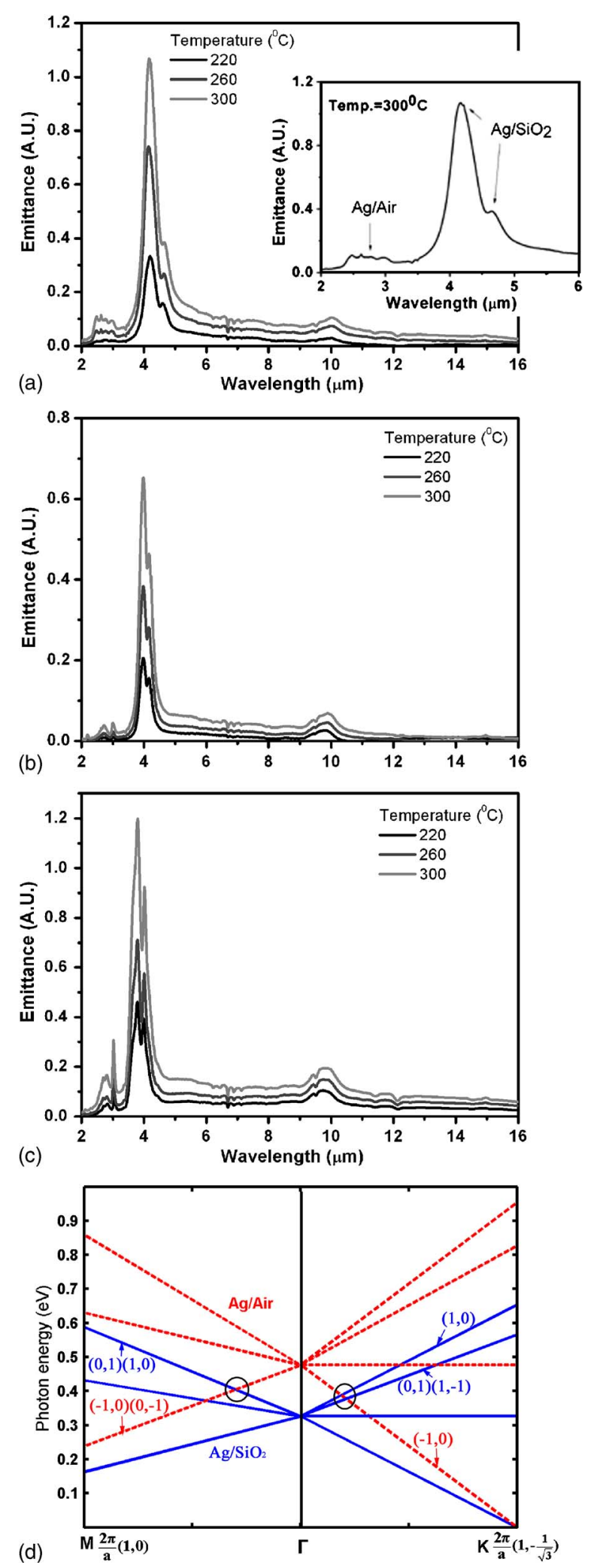

FIG. 2. (Color online) Measured emission spectra of devices (a) A, (b) B, and (c) $\mathrm{C}$ at different temperatures. The inset in (a) shows the enlarged spectrum of device A at the temperature of $300{ }^{\circ} \mathrm{C}$. (d) Calculated energy dispersion relation of SPPs as a function of $\mathbf{k}$ along $\Gamma M$ and $\Gamma K$. Blue solid lines indicate the $\mathrm{Ag} / \mathrm{SiO}_{2}$ modes and red dotted lines indicate the $\mathrm{Ag} / \mathrm{air}$ modes.

a thicker $\mathrm{SiO}_{2}$ layer the resonant modes have a chance to be observed in the emission spectra.

The $(1,0) \mathrm{Ag} / \mathrm{SiO}_{2}$ degenerate modes in devices $\mathrm{A}, \mathrm{B}$, and $\mathrm{C}$ at a temperature of $300{ }^{\circ} \mathrm{C}$ emit at $4.16,3.98$, and
to AIP license or copyright; see http://apl.aip.org/apl/copyright.jsp 
$3.8 \mu \mathrm{m}$, respectively. When the $\mathrm{SiO}_{2}$ thickness is thin, the infrared thermal radiation is generated in this layer and resonant between the upper and bottom $\mathrm{Ag}$ films. This coupling of SPs moves $(1,0) \mathrm{Ag} / \mathrm{SiO}_{2}$ degenerate modes to longer wavelength. When the thickness of the $\mathrm{SiO}_{2}$ layer is greater than the SP coupling length of $\mathrm{Ag} / \mathrm{SiO}_{2}$ mode, the transmission peak wavelengths are close to the predicted value. The $(1,0) \mathrm{Ag} /$ air degenerate modes around $2.45-2.8 \mu \mathrm{m}$ slightly shift to the opposite.

In conclusion, narrow bandwidth infrared thermal emitters were fabricated. The bottom $100 \mathrm{~nm}$ thick $\mathrm{Ag}$ film with very small emissivity can completely reflect the background radiation of the Si substrate and the thermal radiation generated in the $\mathrm{SiO}_{2}$ layer. The FWHM of the $\mathrm{Ag} / \mathrm{SiO}_{2}(1,0)$ degenerate mode is $0.48 \mu \mathrm{m}$. The ratio of the FWHM to the peak wavelength is 0.114 which is small. When the $\mathrm{SiO}_{2}$ thickness exceeds the SP coupling length of $\mathrm{Ag} / \mathrm{SiO}_{2}$ mode, the transmission peak wavelengths are close to the predicted value. The thick $\mathrm{SiO}_{2}$ cause the degenerate $(1,0) \mathrm{Ag} / \mathrm{SiO}_{2}$ modes to split. It can be used as a high temperature operated, narrow bandwidth, and high power infrared light source.

The authors would like to thank the National Science Council of the Republic of China, Taiwan, for financially supporting this research under Contract No. NSC 94-2215E-002-042.

${ }^{1}$ H. F. Ghaemi, Tineke Thio, D. E. Grupp, T. W. Ebbesen, and H. J. Lezec, Phys. Rev. B 58, 6779 (1998).

${ }^{2}$ T. W. Ebbesen, H. J. Lezec, H. F. Ghaemi, T. Thio, and P. A. Wolff, Nature (London) 391, 667 (1998).

${ }^{3}$ S. C. Hohng, Y. C. Yoon, D. S. Kim, V. Malyarchuk, R. Müller, Ch.
Lienau, J. W. Park, K. H. Yoo, J. Kim, H. Y. Ryu, and Q. H. Park, Appl. Phys. Lett. 81, 3239 (2002).

${ }^{4}$ Romain Quidant, Goncal Badenes, Stéphanie Cheylan, Ramon Alcubilla, Jean-Claude Weeber, and Christian Girard, Opt. Express 12, 282 (2004).

${ }^{5}$ Romain Quidant, Dmitri Petrov, and Gonçal Badenes, Opt. Lett. 30, 1009 (2005).

${ }^{6}$ Kevin A. Tetz, Rostislav Rokitski, Maziar Nezhad, and Yeshaiahu Fainman, Appl. Phys. Lett. 86, 111110 (2005).

${ }^{7}$ Shaun M. Williams, Amanda D. Stafford, Trisha M. Rogers, Sarah R. Bishop, and James V. Coe, Appl. Phys. Lett. 85, 1472 (2004).

${ }^{8}$ Sri Priya Sundararajan, Jennifer Marie Steele, and Naomi J. Halas, Appl. Phys. Lett. 88, 063115 (2006).

${ }^{9}$ Tae-In Jeon and D. Grischkowsky, Appl. Phys. Lett. 88, 061113 (2006).

${ }^{10}$ J. W. Lee, M. A. Seo, D. S. Kim, S. C. Jeoung, Ch. Lienau, J. H. Kang, and Q.-Han Park, Appl. Phys. Lett. 88, 071114 (2006).

${ }^{11}$ Nicolas Bonod, Stefan Enoch, Lifeng Li, Popov Evgeny, and Michel Neviere, Opt. Express 11, 482 (2003).

${ }^{12}$ Benfeng Bai, Lifeng Li, and Lijiang Zeng, Opt. Lett. 30, 2360 (2005).

${ }^{13}$ M. U. Pralle, N. Moelders, M. P. McNeal, I. Puscasu, A. C. Greenwald, J. T. Daly, E. A. Johnson, T. George, D. S. Choi, I. El-Kady, and R. Biswas, Appl. Phys. Lett. 81, 4685 (2002).

${ }^{14}$ I. El-Kady, R. Biswas, Y. Ye, M. F. Su, I. Puscasu, Martin Pralle, E. A. Johnson, J. Daly, and A. Greenwald, Photonics Nanostruct. Fundam. Appl. 1, 69 (2003).

${ }^{15}$ Irina Puscasu, M. Pralle, M. McNeal, J. Daly, A. Greenwald, E. Johnson, R. Biswas, and C. G. Ding, J. Appl. Phys. 98, 013531 (2005).

${ }^{16}$ S. Y. Lin, J. Moreno, and J. G. Fleming, Appl. Phys. Lett. 83, 380 (2003).

${ }^{17}$ Shawn-Yu Lin, J. G. Fleming, and I. El-Kady, Appl. Phys. Lett. 83, 593 (2003).

${ }^{18}$ Philippe Ben-Abdallah and Bo Ni, J. Appl. Phys. 97, 104910 (2005).

${ }^{19}$ Ivan Celanovic, David Perreault, and John Kassakian, Phys. Rev. B 72, 075127 (2005).

${ }^{20}$ Y. H. Ye and J. Y. Zhang, Opt. Lett. 30, 1521 (2005).

${ }^{21}$ M. A. Ordal, L. L. Long, R. J. Bell, S. E. Bell, R. R. Bell, R. W. Alexander, Jr., and C. A. Ward, Appl. Opt. 22, 1099 (1983).

${ }^{22}$ Dawn K. Gifford and Dennis G. Hall, Appl. Phys. Lett. 80, 3679 (2002). 